\title{
LA ILICITUD DE LA PRUEBA CON VULNERACIÓN DE DERECHOS FUNDAMENTALES. A PROPÓSITO DE LA SENTENCIA DEL TRIBUNAL CONSTITUCIONAL NÚM. 61/2021 DE 15 DE MARZO ${ }^{1}$
}

\author{
María Desamparados Bohigues Esparza² \\ Personal investigador \\ Universidad de Valencia
}

\begin{abstract}
Una de las cuestiones más controvertidas que se ha suscitado en el ámbito de las relaciones laborales ha sido la relativa a la calificación del despido cuando la prueba se ha obtenido con vulneración de derechos fundamentales. No obstante, no hay que confundir, la nulidad del despido, en la que la extinción tiene como causa un móvil discriminatorio o se produce con violación de derechos fundamentales, con la nulidad de la prueba obtenida con violación de derechos fundamentales. La Sentencia del Tribunal Constitucional núm. 61/2021 de 15 de marzo, objeto de este estudio, aborda esta compleja cuestión, ahora bien, de entrada, cabe destacar, que el Tribunal Constitucional puntualiza que no es objeto del recurso de amparo, ni le corresponde, decidir cuál de esas interpretaciones (improcedencia o nulidad), es la correcta, excediéndose del objeto propio de amparo, que es determinar si en ese ejercicio se ha violado o no, alguna garantía constitucional, si bien, no considera que la decisión de la sentencia impugnada pueda ser tildada de arbitraria o manifiestamente irrazonable.
\end{abstract}

One of the most controversial issues that has arisen in the field of labor relations has been the one related to the qualification of dismissal when the evidence has been obtained in violation of fundamental rights. However, do not confuse the nullity of the dismissal, in which the termination is caused by a discriminatory motive or occurs in violation of fundamental rights, with the nullity of the evidence obtained in violation of fundamental rights. The Decision of the Constitutional Court num. 61/2021 of March 15, the object of this study, addresses this complex issue, however, from the outset, it should be noted that the Constitutional Court points out that it is not the object of the amparo appeal, nor does it correspond to decide which of these interpretations (inadmissibility or nullity), is the correct one, exceeding the object of protection itself, which is to determine whether or not, any constitutional guarantee has been violated in that exercise, although, it does not

\footnotetext{
${ }^{1}$ Personal Investigador (FPU), financiado por el Ministerio de Ciencia, Innovación y Universidades.

${ }^{2}$ La autora es miembro del grupo de investigación reconocido por la Universidad de Valencia DESCLABOR (Desconexión digital en el trabajo), REF. GIUV 2020-473. El presente estudio se inscribe en el marco de trabajo y resultados del citado grupo. https://www.desclabor.com
} 
consider that the decision of the contested judgment can be branded as arbitrary or manifestly unreasonable.

Title: The illegality of the proof with fundamental rights infringement. Comment concerning the Constitutional Court decision $n^{o}$ 61/2021 of March 15 ${ }^{\text {th }}$.

Palabras clave: Prueba ilícita, despido, derechos fundamentales, nulidad, improcedencia. Keywords: Illegal evidence, dismissal, fundamental rights, nullity, inadmissibility.

IUSLabor 2/2021, ISSN 1699-2938, p. 263-287

DOI. 10.31009/IUSLabor.2021.i02.9

Fecha envío: 15.5.2021 | Fecha aceptación: 27.5.2021

\section{Sumario}

1. Introducción

2. El poder de vigilancia y control versus derecho a la intimidad

3. La ilicitud de la prueba con vulneración de derechos fundamentales y la calificación del despido

4. La jurisprudencia del Tribunal Supremo

5. La Sentencia del Tribunal Constitucional núm. 61/2021 de 15 de marzo

6. Conclusiones

7. Bibliografía citada 


\section{Introducción}

Una de las cuestiones más controvertidas que se ha suscitado en el ámbito de las relaciones laborales ha sido la relativa a la calificación del despido cuando la prueba se ha obtenido con vulneración de derechos fundamentales. Y es que, el artículo 55.5 Estatuto de los Trabajadores (ET en adelante), establece que el despido será nulo cuando tenga por móvil alguna de las causas de discriminación prohibidas en la Constitución o en la ley, o bien se produzca con violación de derechos fundamentales y libertades públicas del trabajador.

En este sentido, tanto la doctrina judicial como científica han mantenido posturas contradictorias cuando ha habido vulneración de derechos fundamentales en la obtención de la prueba, y si esa vulneración, únicamente conlleva la ilicitud de la misma, o si también alcanza a todos los actos derivados de dicha prueba, y, por ende, la nulidad del despido.

No obstante, no hay que confundir, la nulidad del despido, en la que la extinción tiene como causa un móvil discriminatorio o se produce con violación de derechos fundamentales, con la nulidad de la prueba obtenida con violación de derechos fundamentales, pues existe una clara separación entre la conducta atentatoria del derecho fundamental al obtener la prueba, y la decisión del despido en el que no se ha vulnerado ningún derecho fundamental, con la consecuencia, de que si la única prueba es ilícita, su ineficacia impedirá que se acredite el incumplimiento, y por tanto, ante un despido sin causa, per se la declaración de improcedencia. Como consecuencia de ello, el resto de pruebas presentadas por el empresario, no se ven afectadas por la nulidad de la prueba ilícita salvo que deriven de la misma ${ }^{3}$.

Pues bien, la Sentencia del Tribunal Constitucional núm. 61/2021 de 15 de marzo, objeto de este estudio, aborda esta compleja cuestión. Sin embargo, de entrada, cabe destacar, que el Tribunal Constitucional puntualiza que no es objeto del recurso de amparo, ni le corresponde, decidir cuál de esas interpretaciones (improcedencia o nulidad), es la correcta, pues en tal caso se estaría efectuando un control de mera legalidad, rectificando la interpretación y aplicación de las normas legales realizadas por los Jueces y Tribunales en el ejercicio exclusivo de la potestad que les reconoce el artículo 117.3 CE, excediéndose del objeto propio de amparo, que es determinar si en ese ejercicio se ha violado o no alguna garantía constitucional.

\footnotetext{
${ }^{3}$ STSJ de Madrid, de 5 de noviembre de 2008, rec. 4747/2008.
} 
Y es que, la doctrina constitucional, ni antes, ni después de esta sentencia, se ha pronunciado expresamente sobre la calificación del despido cuando la prueba ha sido obtenida con vulneración de derechos fundamentales. Ahora bien, como se verá, admitiendo que existen otras interpretaciones posibles, considera que la argumentación de la sentencia impugnada que desvincula la calificación del despido de la nulidad de la prueba obtenida con vulneración de derechos fundamentales no puede ser tildada de arbitraria o manifiestamente irrazonable.

\section{El poder de vigilancia y control versus derecho a la intimidad}

Los sistemas de vigilancia con fines de control laboral se encuentran amparados en el Estatuto de los Trabajadores (en adelante ET), cuyo artículo 20.3 dispone que, "el empresario podrá adoptar las medidas que estime más oportunas de vigilancia y control para verificar el cumplimiento por el trabajador de sus obligaciones y deberes laborales, guardando en su adopción y aplicación la consideración debida a su dignidad y teniendo en cuenta, en su caso, la capacidad real de los trabajadores con discapacidad”.

Así, el empleador, velando por sus legítimos intereses, amparado por el derecho a la libertad de empresa y por el derecho a la propiedad privada reconocidos en la CE, podrá controlar el grado de cumplimiento de las tareas encomendadas a los trabajadores para verificar el cumplimiento de sus obligaciones y deberes laborales.

Por su parte, el artículo 18 ET bajo la rúbrica inviolabilidad de la persona del trabajador establece que, "solo podrán realizarse registros sobre la persona del trabajador, en sus taquillas y efectos particulares, cuando sean necesarios para la protección del patrimonio empresarial y del de los demás trabajadores de la empresa, dentro del centro de trabajo y en horas de trabajo. En su realización se respetará al máximo la dignidad e intimidad del trabajador y se contará con la asistencia de un representante legal de los trabajadores o, en su ausencia del centro de trabajo, de otro trabajador de la empresa, siempre que ello fuera posible".

Sin embargo, en el caso del uso de los medios informáticos, cabe destacar, que no resultan de aplicación las garantías del artículo 18 ET, pues no tienen la consideración de efectos personales, como puede ser la taquilla del vestuario, por tratarse de medios que son propiedad de la empresa. Si bien, deberá informarse al trabajador sobre las políticas de uso prohibido ${ }^{4}$.

\footnotetext{
${ }^{4}$ Ibidem.
} 
Asimismo, el artículo 20 bis E.T., introducido por la Disposición final 13 de la Ley 3/2018, de 5 de diciembre, de Protección de Datos Personales y Derechos Digitales (LOPDGDD en adelante), dispone que, "los trabajadores tienen derecho a la intimidad en el uso de los dispositivos digitales puestos a su disposición por el empleador, a la desconexión digital y a la intimidad frente al uso de dispositivos de videovigilancia y geolocalización en los términos establecidos en la legislación vigente en materia de protección de datos personales y garantía de los derechos digitales".

Cabe destacar, la importancia en materia de derechos digitales de la reciente LOPDGDD, que acomete la tarea de reconocer y garantizar un elenco de derechos digitales de los ciudadanos conforme al mandato establecido en la Constitución.

En efecto, especial relevancia adquiere en esta materia, el artículo 87 de la citada norma, bajo la rúbrica derecho a la intimidad y uso de dispositivos digitales en el ámbito laboral, cuyo apartado 3 dispone que, "el acceso por el empleador al contenido de dispositivos digitales respecto de los que haya admitido su uso con fines privados requerirá que se especifiquen de modo preciso los usos autorizados y se establezcan garantías para preservar la intimidad de los trabajadores, tales como, en su caso, la determinación de los períodos en que los dispositivos podrán utilizarse para fines privados".

Y es que, el derecho a la intimidad según la doctrina del Tribunal Constitucional ${ }^{5}$, supone la existencia de un ámbito propio y reservado frente a la acción y el conocimiento de los demás, y ese ámbito debe respetarse también en el marco de las relaciones laborales, en las que es factible en ocasiones acceder a informaciones atinentes a la vida íntima $\mathrm{i}$ familiar del trabajador que pueden ser lesivas para el derecho a la intimidad.

Por ello, determinadas formas de control de la prestación de servicios pueden resultar incompatibles con ese derecho, porque, aunque no se trata de un derecho absoluto, puede ceder, ante intereses constitucionalmente relevantes. Para ello, como señala la sentencia del Tribunal Supremo de 26 de septiembre de 2007, es necesario que las limitaciones impuestas sean necesarias para lograr un fin legítimo, y sean también proporcionadas para alcanzarlo, y respetuosas con el contenido esencial del derecho ${ }^{6}$.

Así pues, el Tribunal Constitucional ${ }^{7}$ ha mantenido que el ejercicio de las facultades organizativas y disciplinarias del empleador no puede servir en ningún caso a la

\footnotetext{
${ }^{5}$ STC 98/2000, de 10 de abril, rec. 4015/1996; STC 186/2000 de 10 de julio, rec. 2662/1997; STC 142/1993 de 22 de abril, rec. 190/1991.

${ }^{6}$ Rec. núm. 966/2006.

${ }^{7}$ STC 98/2000, de 10 de abril, rec. 4015/1996.
} 
producción de resultados inconstitucionales, lesivos de los derechos fundamentales del trabajador $^{8}$, ni a la sanción del ejercicio legítimo de tales derechos por parte de aquél ${ }^{9}$ debiendo preservar el necesario equilibrio entre las obligaciones dimanantes del contrato para el trabajador y el ámbito (modulado por el contrato, pero en todo caso subsistente) de su libertad constitucional.

Y es que, en el caso del uso de los medios informáticos facilitados por la empresa se producen conflictos que afectan a la intimidad de los trabajadores, tanto en el correo electrónico, en el que la implicación se extiende también, al secreto de las comunicaciones, como en los supuestos de navegación por internet y en el acceso a determinados archivos personales del ordenador, dado el binomio que se produce en su interacción con la vida social y laboral, a saber, la existencia o inexistencia de vulneración del derecho a la intimidad personal, a la información previa y al tratamiento de los datos, en contradicción con las facultades de control y dirección del empresario, en defensa de sus intereses patrimoniales.

En este sentido, la doctrina ${ }^{10}$ ha señalado en qué términos el poder fiscalizador del empleador resulta adecuado, destacando entre ellos, la previa comunicación a los representantes de los trabajadores, diferenciando cuando la medida se ejerce dentro del poder ordinario del cumplimiento de la prestación laboral frente a cuando se ejerce como una medida de vigilancia concreta y extraordinaria, lo que vendría a significar una comunicación genérica de su existencia a trabajadores y representantes en cuanto a la primera se refiere, y cuando se trata de una medida excepcional ex profeso de que se va a adoptar determinado medio de control ante las sospechas o indicios fundados de posibles incumplimientos o ilícitos, necesariamente ha de pasar por la comunicación previa a los representantes de los trabajadores.

En el mismo sentido, como se ha señalado ${ }^{11}$, en cuanto al uso de los medios tecnológicos facilitados por la empresa, o existe una normativa específica convencional o contractual o códigos de conducta prohibiendo el uso personal del mismo específicamente, o lo

\footnotetext{
${ }^{8}$ Entre otras, STC 94/1984 de 16 de octubre, rec. 695/1983; STC 108/1989 de 8 de junio, rec. 1031/1987; STC 171/1989 de 19 de octubre, rec. 479/1987; STC 123/1992 de 28 de septiembre, rec. 301/1989.

${ }^{9}$ STC $11 / 1981$ de 8 de abril, rec. 192/1980.

${ }^{10}$ FABRegat MonforT, Gemma. "El control empresarial de los trabajadores a través de las nuevas tecnologías: algunas ideas clave", Trabajo y Derecho, n 5, 2015, p. 5.

${ }^{11}$ TOSCANI GIMÉNEZ, Daniel. "La validez de la prueba digital o electrónica en el proceso laboral”, en Tomas Sala Franco (dir), Nores Torres, Luís Enrique (coord.), Problemas actuales del proceso laboral. Homenaje al profesor Jose $M^{a}$ Goerlich con ocasión de sus 25 años como Catedrático del Derecho del Trabajo y de la Seguridad Social, Valencia, Tirant Lo Blanch, 2020, p. 357.
} 
contrario, despliega la expectativa de derecho al uso personal en el trabajador, que obligará a la empresa a informar expresamente y con carácter previo.

En el mismo sentido, la Recomendación ${ }^{12}$ adoptada por el Comité de Ministros del Consejo de Europa sobre el procesamiento de datos de carácter personal en el ámbito laboral parece ir en la misma línea cuando declara que la información ha de proporcionarse de una manera accesible y mantenerse actualizada. Y dicha información, en cualquier caso, deberá ser proporcionada antes de que el empleado ejerza efectivamente la actividad o acción prevista.

Así, en su apartado 15 señala que no debería permitirse la utilización de sistemas cuya finalidad principal sea la monitorización de la actividad y el comportamiento de los empleados, y cuando dicha monitorización responda a fines legítimos como puede ser el correcto funcionamiento de la empresa, deberán adoptarse garantías adicionales, incluida la consulta a los representantes de los trabajadores.

Y es que, como ha destacado la doctrina ${ }^{13}$ la regulación de estos derechos no sólo va a reposar en la normativa legal, pues el artículo 91 LOPDGDD dispone que, los convenios colectivos podrán establecer garantías adicionales de los derechos y libertades relacionados con el tratamiento de los datos personales de los trabajadores y la salvaguarda de derechos digitales en el ámbito laboral, es decir, da entrada, como no podía ser de otra forma, a la autonomía colectiva en la determinación del contenido de estos derechos, pues, no cabe duda, que entre sus cometidos, se encuentra implementar el equilibrio entre las desigualdades que puede ocasionar el contrato de trabajo entre el empresario y el trabajador, corrigiéndolas y delimitándolas ${ }^{14}$.

\section{La ilicitud de la prueba con vulneración de derechos fundamentales y la calificación del despido}

Los medios de prueba se encuentran regulados en el artículo 299 de la Ley 1/2000, de 7 de enero, de Enjuiciamiento Civil (en adelante LEC) y en los artículos 90 y ss. de la Ley 36/2011, de 10 de octubre, Reguladora de la Jurisdicción Social (LRJS en adelante), a saber, documentos públicos, documentos privados, pericial, testifical, interrogatorio, o incluso el reconocimiento judicial.

\footnotetext{
${ }^{12}$ CM/Rec. (2015)5 de 1 de abril de 2015.

${ }^{13}$ BAYlos GraU, Antonio Pedro. "Los derechos digitales y la negociación colectiva", Diario La Ley, $\mathrm{n}^{\circ}$ 9331, 2019, p. 2.

${ }^{14}$ Grau PINEDA, Carmen.; MonTESDEOCA SuÁREZ, Arturo. "Reconocer el derecho a la desconexión digital para garantizar el derecho a la intimidad personal y familiar", Revista General de Derecho del Trabajo y de la Seguridad Social, no 57, 2020, p. 26.
} 
Entre los medios probatorios que pueden utilizarse en el proceso laboral cada vez es más frecuente aportar pruebas electrónicas, correos electrónicos, pantallazos o capturas de pantalla, centrándose gran parte de la problemática en determinar su concreto valor probatorio $^{15}$. Sin embargo, a pesar de la frecuencia de su utilización, es significativo que no se mencione de manera expresa con la denominación de prueba electrónica en ningún precepto normativo ${ }^{16}$.No obstante, cabe destacar que el artículo 90.2 LRJS veda aquellas pruebas obtenidas habiéndose vulnerado algún derecho fundamental ${ }^{17}$.

En el ámbito de internet, como se ha señalado ${ }^{18}$, las redes sociales son canales proclives para el ejercicio de la libertad de expresión, sin duda, una de las piedras angulares sobre las que se asienta nuestro sistema constitucional, y que viene directamente reconocido como derecho fundamental. No en vano, nuestro ordenamiento no puede reconocer que bajo el manto de la libertad de expresión queden amparados comentarios injuriosos, ultrajantes o que, en esencia, dañen el honor de otro sujeto.

En efecto, como ha destacado la doctrina ${ }^{19}$, el uso de las redes sociales en gran parte de estos supuestos no implica de por sí un incumplimiento contractual, sino que la red social constituye la vía a través de la cual el incumplimiento se detecta; en otras palabras, la red social funciona, en realidad, como medio de prueba del incumplimiento de que se trate y, desde esa perspectiva, los diferentes problemas que su uso genera, singularmente su admisibilidad y la tensión con el respeto al derecho a la intimidad.

Sobre esta cuestión, es posible afirmar que el número de supuestos en los que las redes sociales juegan un papel relevante a la hora sancionar disciplinariamente a una persona trabajadora se ha visto incrementado considerablemente en los últimos años, destacando especialmente las denominadas redes sociales, tipo Twitter, Facebook, WhastApp, etc ${ }^{20}$. A este respecto, como se ha señalado ${ }^{21}$, cada vez es más frecuente, el acceso por parte de las empresas, a los perfiles personales de sus empleados y empleadas bien a través de las

\footnotetext{
${ }^{15}$ GONZÁLEZ GONZÁLEZ, Carlos. "El valor probatorio de los correos electrónicos", Aranzadi doctrinal, $\mathrm{n}^{\circ}$ 10, 2019, p. 1.

${ }^{16}$ Ibid, op cit., p. 2.

${ }^{17}$ TALENS VISCONTI, Eduardo. "Aspectos jurídicos sobre los comentarios de los trabajadores proferidos a través de las redes sociales", Trabajo y Derecho, no 23, 2016 p. 8.

${ }^{18}$ TALENS VisCONTI, Eduardo. Ibid, op. cit., p. 10.

${ }^{19}$ NORES TORRES, Luis Enrique. "Algunos puntos críticos sobre la repercusión de las redes sociales en el ámbito de las relaciones laborales: aspectos individuales, colectivos y procesales, Revista de Información Laboral, $\mathrm{n}^{\mathrm{O}}$ 7, 2016, p. 18.

${ }^{20}$ Romero Burillo, Ana María. "Las nuevas TIC y el despido disciplinario del trabajador", Revista de Derecho Social, no 85, 2019, p. 44.

${ }^{21}$ Ibidem.
} 
fotos subidas, bien, de los comentarios e información que proporcionan sus autores y autoras, como medio de prueba de la extinción del contrato.

Pues bien, una de las cuestiones más controvertidas que se ha suscitado en el ámbito de los derechos digitales ha sido la relativa a las consecuencias en la calificación del despido cuando la prueba se ha obtenido con vulneración de derechos fundamentales.

Y es que, el artículo 55.5 ET establece que el despido será nulo cuando tenga por móvil alguna de las causas de discriminación prohibidas en la Constitución o en la ley, o bien se produzca con violación de derechos fundamentales y libertades públicas del trabajador.

Por su parte, el artículo 11 de la Ley Orgánica del Poder Judicial (en adelante LOPJ) establece que no surtirán efecto las pruebas obtenidas, directa o indirectamente, violentando los derechos o libertades fundamentales. En el mismo sentido, el artículo 90.2 LRJS establece que no se admitirán pruebas que tuvieran su origen o que se hubieran obtenido, directa o indirectamente, mediante procedimientos que supongan violación de derechos fundamentales o libertades públicas.

Tal norma, como se ha señalado, avala la distinción entre pruebas ilícitas directas, que son las obtenidas con vulneración de derechos fundamentales, e indirectas, que son las conectadas causalmente con las pruebas ilícitas directas, quedando podridas (es la doctrina del fruto del árbol envenenado, o el efecto dominó de la ilicitud de la prueba) ${ }^{22}$

Pues bien, tanto la doctrina judicial como científica han mantenido posturas contradictorias respecto de la calificación del despido cuando ha habido vulneración de derechos fundamentales en la obtención de la prueba, y si esa vulneración, únicamente conlleva la ilicitud de la misma, o si también alcanza a todos los actos derivados de dicha prueba, y, por ende, la nulidad del despido.

En efecto, parte de la doctrina ${ }^{23}$ entiende que una cosa es la ilicitud de la prueba y otra la nulidad del despido, pues si la prueba se ha obtenido ilícitamente, ello debería conllevar la inadmisibilidad de la misma, pero esta ilicitud no debe trasladarse a la calificación del despido, debiendo valorarse la misma, prescindiendo de la prueba declarada ilícita y por ende, la procedencia, improcedencia o nulidad, a la luz de las restantes pruebas.

\footnotetext{
22 LOUSADA AROCHENA, Fernando. "La prueba ilícita en el proceso laboral”, Revista Doctrinal Aranzadi Social, no 11, 2006, p. 1 .

${ }^{23}$ NORES TORRES, Luis Enrique. Ibid, op. cit., p. 29.
} 
Otra parte de la doctrina ${ }^{24}$, considera erróneo o sin "demasiado acierto" la calificación como improcedente del despido acordado cuando es la prueba ilícita, la única prueba, en que la empresa basó el despido.

Sin embargo, como se ha señalado ${ }^{25}$, es evidente que, si la empresa solicita y practica la prueba de interrogatorio de parte, ya no habrá prueba única, con independencia del resultado de su práctica y la valoración de la misma por parte del juez de instancia.

La tesis que defiende la nulidad del despido tiene su base en el artículo 55 ET y en la propia LRJS, y su encaje en el artículo 11.1 LOPJ, pues se entiende que cuando la prueba se ha obtenido vulnerando un derecho fundamental, la nulidad no puede limitarse a la prueba en el proceso, y ello, con base en la íntima conexión que existe entre ambas instituciones, pues es la propia prueba, la que sirve como instrumento para demostrar la existencia de la causa de pedir y por tanto, la institución jurídica a la que se vincula se vicia igualmente de nulidad, y es la única forma de reponer el derecho lesionado ${ }^{26}$, y la declaración de improcedencia y la correspondiente indemnización, no puede ser válida cuando estamos ante una decisión disciplinaria viciada de inconstitucionalidad ${ }^{27}$.

Esta tesis, como se ha señalado ${ }^{28}$, tiene su origen en la jurisprudencia constitucional sobre la prueba prohibida en el orden penal y su afectación al derecho de presunción de inocencia, así como al derecho a un proceso con todas las garantías.

No obstante, no hay que confundir, la nulidad del despido, en la que la extinción tiene como causa un móvil discriminatorio o se produce con violación de derechos fundamentales, con la nulidad de la prueba obtenida con violación de derechos fundamentales, pues existe una clara separación entre la conducta atentatoria del derecho fundamental al obtener la prueba, y la decisión del despido en el que no se ha vulnerado ningún derecho fundamental, con la consecuencia, de que si la única prueba es ilícita, su ineficacia impedirá que se acredite el incumplimiento, y por tanto, ante un despido sin

\footnotetext{
${ }^{24}$ PuRCalla Bonilla, Miguel Ángel. "Control tecnológico de la prestación laboral y derecho a la desconexión de los empleados: Notas a propósito de la Ley 3/2018, de 5 de diciembre”, Revista Española de Derecho del Trabajo, $\mathrm{n}^{\circ} 218,2019$, p. 4-5.

${ }^{25}$ FALGUERA BARÓ, Miguel Ángel. "Nuevas tecnologías y trabajo (y III): perspectiva procesal", Trabajo y Derecho, $\mathrm{n}^{\circ} 22,2016$, p. 7.

${ }^{26}$ Altés TARREGA, Juan Antonio y FitA ORTEGA, Fernando. "La validez de la prueba digital o electrónica en el proceso laboral", en SALA FrANCO, Tomás (dir), y NORES TORRES, Luís Enrique (coord.), Problemas actuales del proceso laboral. Homenaje al profesor Jose $M^{a}$ Goerlich con ocasión de sus 25 años como Catedrático del Derecho del Trabajo y de la Seguridad Social, Valencia, Tirant Lo Blanch, 2020, p. 327.

${ }^{27}$ Ibidem, y bibliografía citada.

${ }^{28}$ Ibid, op. cit., p. 325.
} 
causa, per se la declaración de improcedencia. Como consecuencia de ello, el resto de pruebas presentadas por el empresario, no se ven afectadas por la nulidad de la prueba ilícita salvo que deriven de la misma ${ }^{29}$.

Y es que, como se ha señalado, la doctrina del fruto del árbol envenenado ha perdido su eficacia como concepción extensiva del derecho penal, manteniéndose únicamente una serie de excepciones a la afectación refleja de la prueba ilícita, cuando se rompe con la conexión de antijuridicidad. Es decir, esta conexión queda invalidada cuando existen otros datos que se han obtenido por vías lícitas e independientes ${ }^{30}$.

En definitiva, como ya se afirmó ${ }^{31}$, el ámbito de la calificación de nulidad en nuestro ordenamiento jurídico se reserva de manera muy restrictiva, a la nulidad que tenga por móvil alguna causa de discriminación o vulneración de un derecho fundamental o libertad pública, sin que, en ningún caso, se contemple como causa de nulidad la obtención ilícita de una fuente de prueba, utilizada en el proceso judicial por el trabajador disconforme con la decisión empresarial de despido.

\section{La jurisprudencia del Tribunal Supremo}

En primer lugar, la sentencia del Tribunal Supremo de 26 de septiembre de $2007^{32}$ aun no pronunciándose sobre la calificación del despido cuando se ha obtenido la prueba con vulneración de derechos fundamentales, considera ilícita la prueba obtenida a través del registro del ordenador propiedad de la empresa.

En los hechos probados de la sentencia de instancia consta que el actor, director general de la empresa demandada, prestaba servicios en un despacho sin llave, en el que disponía de un ordenador, carente de clave de acceso y conectado a la red de la empresa. Asimismo, consta la intervención de un técnico informático para comprobar los fallos del ordenador.

Pues bien, en la comprobación realizada por el informático en presencia del administrador de la empresa, se detectó la existencia de virus informáticos, como consecuencia de la navegación por paginas poco seguras de internet, así como la existencia en la carpeta de archivos temporales accesos a determinadas páginas web de contenido pornográfico. Dicho contenido fue almacenado en un dispositivo USB, que se entregó a un notario.

\footnotetext{
${ }^{29}$ STSJ de Madrid, de 5 de noviembre de 2008, rec. 4747/2008.

${ }^{30}$ STS, sala penal, de 3 de abril de 2017, rec. 10612/2016.

${ }^{31}$ GIL Plana, Juan. La prueba en el proceso laboral. Aranzadi Thomson Reuters, Cizur Menor, 2005, p. 219.

${ }^{32}$ Rec. núm. 966/2006.
} 
Posteriormente, la empresa procede a realizar la misma operación con la presencia de los delegados de personal.

La cuestión que se plantea no trata de valorar la conducta del trabajador a efectos disciplinarios, sino resolver un problema previo sobre el alcance y la forma del control empresarial sobre el uso por el trabajador del ordenador que se ha facilitado por la empresa como instrumento de trabajo.

En este sentido, se alude al supuesto decidido por la sentencia de 20 de abril de 2005 , para afirmar que no se está enjuiciando una conducta a efectos disciplinarios desde la perspectiva del alcance de la protección de un derecho fundamental ${ }^{33}$, como sucede en el despido disciplinario que se produce por vulneración del derecho a la libertad sindical desde su vertiente del derecho a la distribución de información sindical.

En efecto, la cuestión suscitada se centra, por tanto, en determinar si las condiciones que el artículo 18 del ET establece para el registro de la persona del trabajador, su taquilla y sus efectos personales, se aplican también al control empresarial sobre el uso por parte del trabajador de los ordenadores facilitados por la empresa.

Y es que, el problema que se plantea, desde la perspectiva de ilicitud de la prueba obtenida vulnerando derechos fundamentales, es la compatibilidad de ese control empresarial con el derecho del trabajador a su intimidad personal (artículo 18.1 CE), o incluso con el derecho al secreto de las comunicaciones (artículo $18.3 \mathrm{CE}$ ), si se tratara del control del correo electrónico.

En el caso del uso por el trabajador de los medios informáticos facilitados por la empresa, como ya se ha dicho, pueden producirse conflictos que afectan a la intimidad de los trabajadores, tanto en el correo electrónico, como en la navegación por internet y en el acceso a determinados archivos personales del ordenador.

Así, esta utilización personalizada se produce como consecuencia de las dificultades prácticas de establecer una prohibición absoluta del empleo personal del ordenador y de la generalización de cierta tolerancia con un uso moderado de los medios de la empresa.

Sin embargo, al mismo tiempo, hay que tener en cuenta que se trata de medios que son propiedad de la empresa, facilitados para el cumplimiento de la prestación laboral, por lo que esa utilización queda dentro del ámbito del poder de vigilancia del empresario,

${ }^{33}$ Rec. núm. 6701/2003. 
respetando en todo caso la consideración debida a la dignidad del trabajador (artículo 18 ET).

No obstante, el artículo 18 ET está atribuyendo al empresario un control que excede del que deriva de su posición en el contrato de trabajo y que, por tanto, queda fuera del marco del artículo 20 ET.

En este sentido, el régimen de registros del artículo 18 ET hace referencia tanto a la persona del trabajador, como a sus efectos personales, como por ejemplo el uso de la taquilla, que forman parte de la esfera privada de aquel y por ende, fuera del control de la ejecución del contrato de trabajo al que se extienden los poderes del artículo 20 ET.

Por el contrario, las medidas de control sobre los medios informáticos puestos a disposición del trabajador se encuentran, en principio dentro del ámbito normal de esos poderes, pues el ordenador es un instrumento de producción del que es titular el empresario, y éste tiene, por tanto, a efectos del cumplimiento de la prestación laboral facultades de control de la utilización, que incluyen lógicamente su examen. No cabe, por tanto, la aplicación de las garantías del artículo 18 ET, si bien, con base en la doctrina sentada por el Tribunal de Derechos Humanos en las sentencias de 25 de junio de 1997, (caso Halford) y de 3 de abril de 2007, (caso Copland), para valorar la existencia de una lesión del artículo 8 del Convenio Europeo para la protección de los derechos humanos, debe informarse al trabajador sobre las políticas de uso prohibido.

Y es que, la actuación de la empresa sin previa advertencia sobre el uso y el control del ordenador, supone la vulneración del derecho a la intimidad del trabajador, y aunque la entrada inicial en el ordenador estaba en principio justificada por la existencia de un virus, la actuación empresarial no se detuvo ante las tareas de detección y reparación, sino que, siguió con el examen del ordenador, con la finalidad de apoderarse de un archivo cuyo examen o control no puede considerarse necesario para la reparación que se pretendía.

Por ello, lo que debe hacer la empresa de acuerdo con las exigencias de buena fe, es establecer previamente las reglas de uso de esos medios - con aplicación de prohibiciones absolutas o parciales- e informar a los trabajadores de que va existir control y de los medios que han de aplicarse en orden a comprobar la corrección de los usos, así como de las medidas que han de adoptarse en su caso para garantizar la efectiva utilización laboral del medio cuando sea preciso, sin perjuicio de la posible aplicación de otras medidas de carácter preventivo, como la exclusión de determinadas conexiones.

En definitiva, la empresa debe anunciar de forma clara e inequívoca que los trabajadores no disponen de intimidad en tales herramientas de trabajo y que se podrán realizar 
controles periódicos sobre esas herramientas, propiedad de la empresa, considerando así, que, en tal caso, queda destruida esa expectativa de intimidad, y por ende, los trabajadores no podrán alegar ese derecho para solicitar la nulidad de las pruebas obtenidas en tales registros ${ }^{34}$.

Posteriormente, en la misma línea, la sentencia del Tribunal Supremo ${ }^{35}$ de 8 de marzo de 2011, al hilo de un despido disciplinario, se pronuncia sobre la ilicitud de la prueba obtenida a través de una auditoría interna del uso de los medios informáticos, puestos a disposición de los trabajadores.

En efecto, la cuestión suscitada gira en torno al uso del ordenador utilizado por los jefes de turno, por las sospechas de la empresa sobre los accesos y/o visitas a internet por parte de los mismos, por lo que decide realizar en los meses de enero y febrero de 2009 una auditoría interna en las redes de la información, con el objeto de revisar la seguridad del sistema y detectar posibles anomalías en la utilización de los medios puestos a disposición de los empleados.

Pues bien, en el periodo de los dos meses indicados, se accedió a internet en horas de trabajo con un total de 5.566 visitas a páginas referidas al mundo multimedia-vídeos, piratería informática, anuncios, televisión, contactos, etc. La gran mayoría de los accesos o visitas a Internet se produjeron en los turnos de trabajo de uno de los trabajadores. A su vez, casi la totalidad de visitas se realizaron en tramos horarios en que el trabajador estaba solo en el despacho.

Ahora bien, la sentencia admite que aunque la prueba ha sido obtenida por la empresa a partir de una auditoría interna en las redes de información con el objetivo de revisar la seguridad del sistema y detectar posibles anomalías en la utilización de los medios informáticos puestos a disposición de los empleados, no consta que, de acuerdo con las exigencias de la buena fe, la empresa hubiera establecido previamente algún tipo de reglas para el uso de dichos medios, con aplicación de prohibiciones absolutas o parciales, ni tampoco que se hubiera informado a los trabajadores de que se iba a proceder al control, ni de los medios a aplicar, en orden a comprobar su correcto uso, por lo que declara la ilicitud de la prueba obtenida con vulneración de derechos fundamentales.

\footnotetext{
34 Todolí SigneS, Adrián. "El registro informático como base para el despido. Cuestiones fundamentales", Revista Aranzadi de Derecho y Nuevas Tecnologías, nº 25, 2011, p. 5.

${ }^{35}$ Rec. núm. 1825/2010.
} 
Especial relevancia sobre esta materia se contiene en la sentencia del Tribunal Supremo de 6 de octubre de $2011^{36}$, pues a diferencia de la examinada anteriormente, en el supuesto enjuiciado, existía una prohibición absoluta, que válidamente impuso el empresario sobre el uso de medios de la empresa (ordenadores, móviles, internet, etc.) para fines propios, tanto dentro como fuera del horario de trabajo, por las sospechas fundadas de que se estaban desobedeciendo las órdenes impartidas al respecto.

En efecto, la empresa entregó a todos los trabajadores una carta en la que se comunicaba que quedaba terminantemente prohibido el uso de medios de la empresa (ordenadores, móviles, internet, etc) para fines propios, tanto dentro como fuera del horario de trabajo.

Pues bien, en el mes de enero de 2006 decidió hacer una comprobación sobre el uso de sus medios de trabajo, para lo que procedió a la monitorización de los ordenadores de la trabajadora demandante y de otra trabajadora, encargando la instalación de un software de monitorización. Se trataba de un sistema pasivo, poco agresivo, que no permitía acceder a los archivos del ordenador que están protegidos por contraseñas de cada uno de los usuarios.

Posteriormente, en el mes de febrero la empresa procedió a visualizar el proceso de monitorización del ordenador de la demandante en presencia de ésta, de las dos personas que habían procedido a la instalación del software, de los representantes de la empresa y también de los representantes de los trabajadores, así como de otros dos trabajadores, firmándose al efecto un acta, con excepción de la demandante.

La cuestión clave admitida la facultad de control del empresario, y la licitud de una prohibición absoluta de los usos personales, consiste en determinar si existe o no un derecho del trabajador a que se respete su intimidad cuando, en contra de la prohibición del empresario o con una advertencia expresa o implícita de control, utiliza el ordenador para fines personales.

La respuesta parece clara, desde la perspectiva de que si no hay derecho a utilizar el ordenador para usos personales, no habrá tampoco derecho para hacerlo en unas condiciones que impongan un respeto a la intimidad o al secreto de las comunicaciones, porque, al no existir una situación de tolerancia del uso personal, tampoco exista ya, una expectativa razonable de intimidad, y porque, si es uso personal es ilícito, no puede exigirse al empresario que lo soporte y que además se abstenga de controlarlo.

${ }^{36}$ Rec. núm. 4053/2010. 
Por tanto, sentada la validez de prohibición tan terminante, que lleva implícita la advertencia sobre la posible instalación de sistemas de control del uso del ordenador, no es posible admitir que surja un derecho del trabajador a que se respete su intimidad en el uso del medio informático puesto a su disposición, pues tal entendimiento equivaldría a admitir que el trabajador podría crear, a su voluntad y libre albedrío, un reducto de intimidad, utilizando un medio cuya propiedad no le pertenece, y en cuyo uso, está sujeto a las instrucciones del empresario de acuerdo con lo dispuesto en el artículo 20 ET.

Y siguiendo la línea de su predecesora, en consonancia con la doctrina establecida, determina que, el procedimiento que la empresa para realizar el control del uso del ordenador facilitado por ella al trabajador, de acuerdo con las exigencias de la buena fe, debe: a) establecer previamente las reglas de uso de esos medios -los proporcionados por la empresa-, con aplicación de prohibiciones absolutas o parciales; b) informar a los trabajadores de que va a existir control y de los medios que han de aplicarse en orden a comprobar la corrección de los usos, así como de las medidas que han de adoptarse, en su caso, para garantizar la efectiva utilización laboral del medio, cuando sea preciso; c) posibilidad de aplicar otras medidas de carácter preventivo, como la exclusión de determinadas conexiones.

Asimismo, se aclara que la sentencia de 26 de septiembre de 2007, no se aparta de esta conclusión, pues en ella no se contenía una prohibición expresa y absoluta sobre el uso personal de los instrumentos informáticos puestos a disposición del trabajador, y es que, como reitera la sentencia citada, la tolerancia de la empresa es la que crea una expectativa de confidencialidad y, por ende, la posibilidad de un exceso en el control llevado a cabo por el empleador que conlleva la vulneración del derecho fundamental de la intimidad del trabajador.

Sin embargo, la sentencia cuenta con un voto particular ${ }^{37}$, que discrepa de la decisión mayoritaria, al entender que no se dio cumplimiento a la previsión contenida en el apartado b), ya que la empresa no informó a los trabajadores de que iba a existir un control, ni de los medios que iban a utilizar para comprobar la corrección del uso del ordenador, pues procedió a monitorizar el ordenador de las dos trabajadoras, realizando la instalación del software al final de la jornada, una vez que la actora abandonó la empresa.

\footnotetext{
${ }^{37}$ Voto particular formulado por la Magistrada Excma. Sra. Da María Luisa Segoviano Astaburuaga, al que se adhieren los Excmos. Sres. Magistrados D. Luis Fernando De CASTRo Fernández, D. Jordi Agustí JULIA, Da Rosa María VIROLES PIÑol y D. Manuel Ramón AlarCón CARACUEl.
} 
Por tanto, al haberse realizado el control empresarial sin advertir previamente de los controles y medidas aplicables, consideran que se ha vulnerado "una expectativa razonable de intimidad", ya que no es suficiente la prohibición del uso del ordenador para actividades privadas, sino que, tal como ha venido entendiendo la doctrina de la Sala, dicha prohibición ha de ir acompañada de una información sobre la existencia de un control y de los medios que van a aplicarse.

Por último, cabe destacar otro pronunciamiento más reciente, que se contiene en la sentencia del Tribunal Supremo de 8 de febrero de $2018^{38}$, en el que se sustancia un supuesto de despido disciplinario, dictado en unificación de doctrina, que estima el recurso formulado por Inditex, SA, declarando la procedencia del despido, atribuyendo plena validez procesal a la prueba derivada del examen del correo electrónico existente en el ordenador del trabajador, tras un hallazgo casual de fotocopias de las transferencias efectuadas por un proveedor de la empresa en favor del trabajador demandante, hecho expresamente prohibido en el Código de Conducta de la empresa e imputado en la carta de despido.

Pues bien, con fundamento en la doctrina ya expuesta, señalando como decisión de contraste la STC 170/2013, de 7 de octubre, en la que el intérprete máximo de la Constitución rechaza el amparo demandado por el trabajador al que se le había imputado como causa de despido el uso de su ordenador personal para fines personales, basándose en que mediaba expresa prohibición de uso extralaboral de los medios informáticos propiedad de la empresa.

$Y$ es que, en el supuesto examinado, los empleados deben de aceptar las directrices establecidas en la Política de Seguridad de la Información del Grupo Inditex, en la que se señala que el acceso lo es para fines estrictamente profesionales, reservándose la empresa el derecho de adoptar las medidas de vigilancia y control necesarias para comprobar la correcta utilización de las herramientas que pone a disposición de su empleados, respetando en todo caso la legislación laboral y convencional sobre la materia y garantizando la dignidad e intimidad del empleado, por lo que el actor era conocedor de que no podía utilizar el correo para fines particulares y que la empresa podía controlar el cumplimiento de las directrices en el empleo de los medios informáticos por ella facilitados.

${ }^{38}$ Rec. núm. 1121/2015. 


\section{La Sentencia del Tribunal Constitucional núm. 61/2021 de 15 de marzo, rec.6838/2019}

En primer lugar, cabe destacar, que la doctrina constitucional, ni antes, ni después de esta sentencia, se ha referido expresamente sobre la calificación del despido cuando la prueba ha sido obtenida con vulneración de derechos fundamentales.

En efecto, el Tribunal Constitucional puntualiza que no es objeto del recurso de amparo, ni le corresponde, decidir cuál de esas interpretaciones (improcedencia o nulidad), es la correcta, pues en tal caso se estaría efectuando un control de mera legalidad, rectificando la interpretación y aplicación de las normas legales realizadas por los Jueces y Tribunales en el ejercicio exclusivo de la potestad que les reconoce el artículo 117.3 CE, excediéndose del objeto propio de amparo, que es determinar si en ese ejercicio se ha violado o no alguna garantía constitucional.

Pues bien, una vez realizada esta apreciación, los hechos relevantes para la resolución del recurso de amparo, son los siguientes:

a) La demandante venía prestando servicios por cuenta y bajo la dependencia de la entidad Amadeus Soluciones Tecnológicas, S.A., desde el 19 de abril de 1979 con categoría profesional de project office. En dicha empresa se aplicaban normas de uso aceptable de los sistemas de información, de internet y del correo electrónico, que eran conocidas por la recurrente de amparo.

b) El 26 de abril de 2017 la citada empresa comunicó a la demandante la instrucción de un expediente disciplinario conforme al pliego de cargos en que se le atribuían diversos incumplimientos de la buena fe contractual, desobediencia a las instrucciones de sus superiores jerárquicos y ofensas a los mismos.

c) El 8 de mayo de 2017, tras las correspondientes alegaciones, la empresa notificó por escrito a la demandante de amparo su despido disciplinario.

Ante tales circunstancias, y que varios trabajadores, compañeros de la recurrente, habían puesto determinados hechos en conocimiento de la empresa, la empleadora decidió poner en práctica el protocolo de monitorización de su equipo informático con el fin de determinar en qué empleaba su jornada laboral y más particularmente, cuál era su ocupación y si esta era lo suficiente completa como para no poder dedicar parte de su jornada laboral a las funciones que la Compañía le estaba encomendando. 
La pretensión de amparo se fundamenta en los siguientes preceptos que considera infringidos por la Sentencia del Tribunal de Justicia de la Sección Cuarta de la Sala de lo Social del Tribunal Superior de Justicia de Madrid de 13 de septiembre de 2018, dictada en el recurso de suplicación núm. 351/2018, y frente al auto de fecha 24 de septiembre de 2019 dictado por la Sala de lo Social del Tribunal Supremo.

En primer lugar, alega la existencia de la vulneración de su dignidad (artículo 10.1 CE) y de su derecho fundamental a la intimidad y al secreto de las comunicaciones (artículo 18.1 y $3 \mathrm{CE}$ ) como consecuencia de la monitorización del ordenador y de la entrada en su correo personal y en los correos electrónicos con su letrada.

En segundo lugar, considera la existencia de la vulneración de sus derechos a la integridad moral (artículo $15 \mathrm{CE}$ ), del derecho al honor y a la propia imagen personal y profesional (artículo 18.1 CE). Y nuevamente, de la dignidad humana (artículo 10.1 CE), como consecuencia del acoso laboral sufrido por la empresa.

Por último, con cita del artículo 183 de la LRJS, la demandante solicitó en atención a las circunstancias fácticas descritas y a la suma gravedad de la lesión efectivamente producida, una indemnización por los daños materiales y morales producidos por la intromisión ilegítima llevada a cabo. Para cuantificar el importe de la misma, remite a lo previsto en el artículo 40.1 c) del Real Decreto Legislativo 5/2000, de 4 de agosto, por el que se aprueba el texto refundido de la Ley de Infracciones y Sanciones en el Orden Social, para los actos contrarios al respeto de la intimidad y consideración debida a la dignidad de los trabajadores, recogidos como infracciones muy graves en el artículo 8.11 y 12 del mismo texto legal.

Pues bien, respecto de la calificación del despido, el TRIBUNAL CONSTICIONAL adelanta que del contenido esencial de los derechos fundamentales a la intimidad y al secreto de las comunicaciones ( artículo 18.1 y $3 \mathrm{CE}$ ), cuya lesión extraprocesal ha sido reconocida tanto por la sentencia del Juzgado de lo Social núm. 19 de Madrid, como por la Sala de lo Social del Tribunal Superior de Justicia de Madrid, no dimana ni una exigencia, ni un derecho subjetivo que pueda amparar la calificación del despido disciplinario de la demandante de amparo como nulo, sin que de ello, quepa deducir que la calificación del despido sea ajena o indiferente al ámbito de los derechos fundamentales, en concreto al derecho a la tutela judicial efectiva ( artículo 24.1 CE).

En este sentido, el Tribunal Constitucional con cita en la STC 114/1984, de 29 de noviembre (recientemente recordada en el FJ $2^{\circ}$ de la STC 97/2019, de 16 de julio, dictada por el Pleno), respecto de la regla de exclusión probatoria en el ámbito de un despido laboral, en relación con la calificación del despido disciplinario, establece que, "el 
razonamiento del actor parece descansar en la equivocada tesis de que existe una correlación lógica y jurídica entre la posible lesión extraprocesal de su derecho fundamental y la pretendida irregularidad procesal de admitir la prueba obtenida a partir de aquella lesión. Sin embargo, el acto procesal podrá haber sido o no conforme a Derecho, pero no cabe considerarlo como atentatorio, de modo directo, de los derechos reconocidos en el artículo 18.3 de la Constitución", pues si se acogiese esta tesis "habría que concluir que el contenido esencial de todos y cada uno de los derechos fundamentales abarcaría no ya sólo la esfera de libertad o la pretensión vital en que los mismos se concretan, sino también la exigencia, con alcance de derecho subjetivo de no reconocer eficacia jurídica a las consecuencias de cualquier acto atentatorio de tales derechos" (STC 114/1984, FJ 1).

Por tanto, el Tribunal Constitucional determina que no puede proclamarse que entre la calificación del despido y la reconocida lesión extraprocesal de un derecho fundamental pueda afirmarse la existencia de una "consecutividad lógica y jurídica".

Dicho, de otro modo, "no existe un derecho constitucional a la calificación del despido laboral como nulo, por lo que la pretensión de la actora no puede tener sustento en una vulneración de los derechos reconocidos en el artículo 18.1 y 3 CE. Tampoco puede imputarse a la resolución impugnada una conculcación de los derechos de la recurrente a la intimidad y al secreto de las comunicaciones, máxime cuando han sido los órganos judiciales quienes han reconocido que dicha vulneración se produjo con la monitorización del ordenador de la trabajadora".

Considera la sentencia impugnada que la decisión extintiva acordada por la empresa demandada, en si misma considerada, no pretendía la vulneración de derechos fundamentales o libertades públicas de la trabajadora, y que el móvil del empresario al acordar el despido no respondió a una causa vulneradora de los derechos fundamentales lo que legalmente llevaría aparejada la nulidad del despido.

Distingue por tanto los supuestos en que la decisión extintiva vulnera un derecho fundamental, de aquellos otros en los que el empresario, al intentar comprobar el comportamiento de su empleada y obtener pruebas de algunos de sus incumplimientos para tratar de justificar un despido, ha vulnerado los derechos fundamentales de la trabajadora. Indica que no puede confundirse el despido con violación de derechos fundamentales, con el despido en el que ha habido una lesión de los derechos fundamentales en el proceso de obtención de la prueba.

Tampoco puede afirmarse, como bien destacan en sus alegaciones el Ministerio Fiscal y la representación de Amadeus Soluciones Tecnológicas, S.A., que la pretensión de la 
demandante de amparo de que se declare la nulidad del despido pueda tener sustento en las citadas SSTC 125/2018 y 92/2008. En efecto, en los casos examinados por dichas sentencias la decisión extintiva del contrato de las trabajadoras vino motivada bien por el ejercicio legítimo de su derecho de participación política reconocido en el artículo 23.2 $\mathrm{CE}$, bien por razones de discriminación por sexo, sin que se apreciara la ilicitud de prueba alguna.

Por otra parte, no puede considerarse que la declaración de nulidad pretendida pueda ampararse en la STC 196/2004, de 15 de noviembre. En esta sentencia se reconoció que la prueba del despido disciplinario se sustentaba en el resultado de una exploración clínica obtenida con vulneración del derecho a la intimidad personal (artículo 18.1 CE) y se acordó la nulidad del despido basándose en la constante doctrina de este tribunal ${ }^{39}$, pero ninguna de las sentencias en las que sustenta dicha nulidad, se refirieren a un supuesto de prueba ilícita, sino de extinción de la relación laboral por razones discriminatorias y/o lesivas de los derechos a la libertad sindical y de la libertad de expresión.

Por consiguiente, la solución adoptada por la resolución impugnada desvinculando la nulidad de la prueba obtenida con vulneración de los derechos fundamentales de la calificación del despido, tiene anclaje positivo en nuestro ordenamiento jurídico, sin que pueda ser calificada de arbitraria o manifiestamente irrazonable, y, por ende, no supone la vulneración del derecho de tutela judicial efectiva.

Sin embargo, como ya se ha adelantaba al inicio de este estudio y admitiendo que existen otras interpretaciones posibles, "no es objeto del recurso de amparo ni corresponde a este tribunal, que no es una tercera instancia, decidir cuál de esas interpretaciones es la correcta", y de admitir lo contrario, "el recurso de amparo quedaría transformado en una nueva instancia revisora con merma de las competencias que constitucionalmente corresponden a la jurisdicción ordinaria".

En definitiva, la argumentación de la sentencia impugnada que desvincula la calificación del despido de la nulidad de la prueba obtenida con vulneración de derechos fundamentales no puede ser tildada de arbitraria o manifiestamente irrazonable.

En consecuencia, el Tribunal Constitucional únicamente considera la vulneración del derecho de tutela judicial efectiva garantizado en el artículo 24.1 CE, por cuanto la sentencia impugnada desestimó la fijación de cualquier indemnización, negando incluso la reconocida por el juzgado de lo social, al considerar que dicha indemnización se había

\footnotetext{
${ }^{39}$ Entre otras, SSTC 38/1981, de 23 de noviembre; 114/1989, de 22 de junio; 186/1996, de 25 de noviembre; 1/1998, de 12 de enero; 57/1999, de 12 de abril; 20/2002, de 28 de enero; 49/2003, de 17 de marzo.
} 
vinculado, tanto en la demanda como en la sentencia, a la existencia de una vulneración por la empresa de derechos fundamentales de la trabajadora "y como tal lesión no ha existido (no hay prueba del acoso laboral y el despido ha sido calificado de improcedente), no procede indemnización alguna y en consecuencia no procede entrar a conocer de este aspecto del recurso, que debe ser desestimado al faltar el presupuesto del que se parte en el mismo".

Por consiguiente, el argumento utilizado en la resolución impugnada para denegar la indemnización consistente en afirmar que no ha existido vulneración de derechos fundamentales de la trabajadora debe ser calificado de incongruente, ilógico y contradictorio, pues la propia sentencia reconoce, que se vulneraron los derechos fundamentales de la trabajadora al monitorizar su ordenador.

En efecto, la sentencia afirma la existencia de la vulneración de los derechos fundamentales a los efectos de confirmar la exclusión de la prueba derivada de la monitorización del ordenador, y al mismo tiempo niega esa vulneración cuando tiene que decidir sobre la indemnización solicitada y dicha incongruencia no puede salvarse con la referencia a que la vulneración no la haya ocasionado el acto mismo del despido y en consecuencia este haya sido declarado improcedente, pues el artículo 183.1 LRJS cuando dispone que la sentencia que declare la existencia de una vulneración de un derecho fundamental debe pronunciarse sobre la cuantía de la indemnización, no hace depender el reconocimiento de la indemnización de la calificación del despido, sino del reconocimiento de que la trabajadora ha sufrido discriminación u otra lesión de sus derechos fundamentales y libertades públicas, y ello con independencia de la calificación del despido.

Por todo ello, el Tribunal Constitucional estima parcialmente el recurso de amparo por vulneración del derecho de tutela judicial efectiva y procede a restablecer a la recurrente en la integridad de su derecho, y a tal fin, anula la sentencia dictada el 13 de septiembre de 2018 por la Sección Cuarta de la Sala de lo Social del Tribunal Superior de Justicia de Madrid, en el recurso de suplicación número 351/2018, y en consecuencia, acuerda la retroacción de las actuaciones al momento previo al dictado de la citada resolución, a fin de que, en congruencia con lo interesado en el recurso de suplicación, en relación con la indemnización solicitada por la demandante por la vulneración de los derechos a la intimidad y al secreto de las comunicaciones (artículo 18.1 y $3 \mathrm{CE}$ ) ocasionados por la monitorización de su ordenador, el órgano judicial resuelva de manera respetuosa con el derecho fundamental vulnerado.

Por último, cabe destacar, que la nulidad no se extiende al auto del Tribunal Supremo, que inadmitió el recurso de casación para la unificación de doctrina interpuesto contra la 
sentencia de suplicación, y que ha servido, en este caso, para agotar la vía judicial previa al amparo, al que no se le reprocha vulneración autónoma de derecho alguno.

\section{Conclusiones}

En primer lugar, del análisis efectuado, se puede afirmar que la cuestión suscitada, ya de antaño, sobre la calificación del despido cuando la prueba se ha obtenido con vulneración de derechos fundamentales, sigue planteando algunos problemas interpretativos. Si bien, los distintos pronunciamientos dictados por el Tribunal Supremo en esta materia, parece que se inclinan por la separación o diferenciación que debe existir entre la prueba obtenida con vulneración de derechos fundamentales, y el despido que se produce por vulneración de derechos fundamentales.

En el mismo sentido, cabría afirmar que el Tribunal Constitucional se mueve en la misma línea, cuando afirma que la solución adoptada por la resolución impugnada desvinculando la nulidad de la prueba obtenida con vulneración de los derechos fundamentales de la calificación del despido, tiene anclaje positivo en nuestro ordenamiento jurídico, sin que pueda ser calificada de arbitraria o manifiestamente irrazonable, y, por ende, no supone la vulneración del derecho de tutela judicial efectiva.

Por consiguiente, como se ha dicho al inicio de este estudio, aunque el Tribunal Constitucional no se pronuncia expresamente sobre la calificación del despido cuando ha habido vulneración de derechos fundamentales en la obtención de la prueba, considera que la decisión de la sentencia del Tribunal Superior de Justicia de Madrid, de 13 de septiembre de 2018, dictada en el recurso de suplicación núm. 351/2018, impugnada por la recurrente de amparo, no puede ser tildada de arbitraria o manifiestamente irrazonable.

En segundo lugar, cabe destacar que, en el ámbito laboral, adquiere especial relevancia la cuestión relativa al deber de información, principalmente cuando se trata de comprobar la comisión de ilícitos por parte de los trabajadores y por ende la imposición de la correspondiente sanción. Y si bien es cierto que habrán de ponderarse los elementos necesarios para determinar la existencia del juicio de proporcionalidad y necesidad que establece el Tribunal Constitucional, el deber de informar se configura como el elemento indispensable para valorar si la intromisión está justificada o es ilícita, y si ésta, afecta o no, a la esfera personal y privada del trabajador.

Por ello, considero el papel de la negociación colectiva como factor determinante, a los efectos de establecer las garantías adicionales establecidas en la LOPDGDD, pues es fundamental que el trabajador tenga un conocimiento claro de la información que se 
proporciona, siendo esto, el único elemento preponderante para hacer efectivo el deber de informar y con este, la salvaguarda del derecho fundamental agredido.

Y es que, el papel de la negociación colectiva en la regulación de las "garantías adicionales" y su participación en el establecimiento de los criterios de utilización de los medios digitales en el ámbito laboral, adquiere una especial relevancia en esta materia, cuando está en juego la vulneración de un derecho fundamental.

Así pues, no debería permitirse la utilización de sistemas tecnológicos cuya finalidad principal sea la monitorización de la actividad y el comportamiento de los empleados. Y, cuando dicha monitorización responda a fines legítimos como puede ser el correcto funcionamiento de la empresa, deberán adoptarse garantías adicionales, incluida la participación de los representantes de los trabajadores.

En todo caso, el ejercicio de las facultades organizativas y disciplinarias del empleador no puede servir en ningún caso a la producción de resultados inconstitucionales, lesivos de los derechos fundamentales del trabajador, debiendo preservar el necesario equilibrio entre las obligaciones dimanantes del contrato para el trabajador y el ámbito (modulado por el contrato, pero en todo caso subsistente) de su libertad constitucional.

\section{Bibliografía}

Altés Tarrega, Juan Antonio, y FitA Ortega, Fernando, "La validez de la prueba digital o electrónica en el proceso laboral”, en SALA FRANCO, Tomás (dir), y NORES TORRES, Luís Enrique (coord.), Problemas actuales del proceso laboral. Homenaje al profesor Jose $M^{a}$ Goerlich con ocasión de sus 25 años como Catedrático del Derecho del Trabajo y de la Seguridad Social, Valencia, Tirant Lo Blanch, 2020, p. 313-340.

Baylos GraU, Antonio Pedro, "Los derechos digitales y la negociación colectiva", Diario La Ley, nº 9331, 2019, p. 1-4.

FABREGAT MONFORT, Gemma, "El control empresarial de los trabajadores a través de las nuevas tecnologías: algunas ideas clave", Trabajo y Derecho, $n^{\circ}$ 5, 2015, p. 1-8.

FAlguera BARó, Miguel Ángel, "Nuevas tecnologías y trabajo (y III): perspectiva procesal", Trabajo y Derecho, no 22,2016 , p. 1-15.

GIL PlanA, Juan, La prueba en el proceso laboral. Aranzadi Thomson Reuters, Cizur Menor, 2005. 
GonZÁLEZ GonZÁLEZ, Carlos, "El valor probatorio de los correos electrónicos", Aranzadi doctrinal, $\mathrm{n}^{\circ}$ 10, 2019, p. 1-24.

Grau PinedA, Carmen, y Montesdeoca SuÁrez, Arturo, "Reconocer el derecho a la desconexión digital para garantizar el derecho a la intimidad personal y familiar", Revista General de Derecho del Trabajo y de la Seguridad Social, n 57, 2020, p. 1-49.

Lousada ArochenA, Fernando, "La prueba ilícita en el proceso laboral", Revista Doctrinal Aranzadi Social, no 11, 2006, p. 1-14.

NORES TORRES, Luis Enrique, “Algunos puntos críticos sobre la repercusión de las redes sociales en el ámbito de las relaciones laborales: aspectos individuales, colectivos y procesales, Revista de Información Laboral, nº 7, 2016, p. 1-36.

Purcalla Bonilla, Miguel Ángel, "Control tecnológico de la prestación laboral y derecho a la desconexión de los empleados: Notas a propósito de la Ley 3/2018, de 5 de diciembre", Revista Española de Derecho del Trabajo, n² 218, 2019, p. 1-28.

Romero Burillo, Ana María, "Las nuevas TIC y el despido disciplinario del trabajador", Revista de Derecho Social, no 85, 2019, p. 31-54.

TALENS Visconti, Eduardo, "Aspectos jurídicos sobre los comentarios de los trabajadores proferidos a través de las redes sociales", Trabajo y Derecho, no 23, 2016, p. $1-15$.

Todolí Signes, Adrián, "El registro informático como base para el despido. Cuestiones fundamentales", Revista Aranzadi de Derecho y Nuevas Tecnologías, n 25, 2011, p. 114.

TOSCANi GimÉnEZ, Daniel, "La validez de la prueba digital o electrónica en el proceso laboral", en SALA FRAnCO, Tomás (dir), y NORES TORRES, Luís Enrique (coord.), Problemas actuales del proceso laboral. Homenaje al profesor Jose $M^{a}$ Goerlich con ocasión de sus 25 años como Catedrático del Derecho del Trabajo y de la Seguridad Social, Valencia, Tirant Lo Blanch, 2020, p. 341-364. 